\title{
TGF- $\beta$ Induced CTGF Expression in Human Lung Epithelial Cells through ERK, ADAM17, RSK1, and C/EBP $\beta$ Pathways
}

\author{
Shu-Ching Ou ${ }^{1,+}{ }^{\dagger}$ Kuan-Jen Bai ${ }^{1,2,+}{ }^{\dagger}$, Wun-Hao Cheng ${ }^{3,4}$, Jing-Yun Chen ${ }^{3}$, Chien-Huang Lin ${ }^{3}$, \\ Heng-Ching Wen ${ }^{1}$ and Bing-Chang Chen ${ }^{1,2,3,5, *}$ \\ 1 School of Respiratory Therapy, College of Medicine, Taipei Medical University, Taipei 110, Taiwan; \\ m141106001@tmu.edu.tw (S.-C.O.); bkj@tmu.edu.tw (K.-J.B.); d119099014@tmu.edu.tw (H.-C.W.) \\ 2 Division of Pulmonary Medicine, Department of Internal Medicine, Wan Fang Hospital, \\ Taipei Medical University, Taipei 110, Taiwan \\ 3 Graduate Institute of Medical Sciences, College of Medicine, Taipei Medical University, Taipei 110, Taiwan; \\ d119106011@tmu.edu.tw (W.-H.C.); d119104008@tmu.edu.tw (J.-Y.C.); chlin@tmu.edu.tw (C.-H.L.) \\ 4 Respiratory Therapy, Division of Pulmonary Medicine, Department of Internal Medicine, \\ Wan Fang Hospital, Taipei Medical University, Taipei 110, Taiwan \\ 5 Department of Internal Medicine, School of Medicine, College of Medicine, Taipei Medical University, \\ Taipei 110, Taiwan \\ * Correspondence: bcchen@tmu.edu.tw; Tel.: +886-2-27361661; Fax: +886-2-27391143 \\ $\dagger$ These authors contributed equally to this work.
}

Received: 21 September 2020; Accepted: 26 November 2020; Published: 29 November 2020

\begin{abstract}
Background: Lung epithelial cells play critical roles in idiopathic pulmonary fibrosis. Methods: In the present study, we investigated whether transforming growth factor- $\beta$ (TGF- $\beta$ )-induced expression of connective tissue growth factor (CTGF) was regulated by the extracellular signal-regulated kinase (ERK)/a disintegrin and metalloproteinase 17 (ADAM17)/ ribosomal S6 kinases 1 (RSK1)/CCAAT/enhancer-binding protein $\beta(\mathrm{C} / \mathrm{EBP} \beta)$ signaling pathway in human lung epithelial cells (A549). Results: Our results revealed that TGF- $\beta$-induced CTGF expression was weakened by ADAM17 small interfering RNA (ADAM17 siRNA), TNF- $\alpha$ processing inhibitor-0 (TAPI-0, an ADAM17 inhibitor), U0126 (an ERK inhibitor), RSK1 siRNA, and C/EBP $\beta$ siRNA. TGF- $\beta$-induced ERK phosphorylation as well as ADAM17 phosphorylation was attenuated by U0126. The TGF- $\beta$-induced increase in RSK1 phosphorylation was inhibited by TAPI-0 and U0126. TGF- $\beta$-induced C/EBP $\beta$ phosphorylation was weakened by U0126, ADAM17 siRNA, and RSK1 siRNA. In addition, TGF- $\beta$ increased the recruitment of C/EBP $\beta$ to the CTGF promoter. Furthermore, TGF- $\beta$ enhanced fibronectin (FN), an epithelial-mesenchymal transition (EMT) marker, and CTGF mRNA levels and reduced E-cadherin mRNA levels. Moreover, TGF- $\beta$-stimulated FN protein expression was reduced by ADAM17 siRNA and CTGF siRNA. Conclusion: The results suggested that TGF- $\beta$ induces CTGF expression through the ERK/ADAM17/RSK1/C/EBP $\beta$ signaling pathway. Moreover, ADAM17 and CTGF participate in TGF- $\beta$-induced FN expression in human lung epithelial cells.
\end{abstract}

Keywords: pulmonary fibrosis; transforming growth factor- $\beta$; a disintegrin and metalloproteinase 17; connective tissue growth factor; epithelial-mesenchymal transition

\section{Introduction}

Idiopathic pulmonary fibrosis (IPF) is a type of an interstitial lung disease that is prevalent in elder smokers. The phases of IPF include alveolar epithelial cell damage and activation, inflammatory cell infiltration, epithelial-mesenchymal transition (EMT) initiation, and ECM protein accumulation [1]. 
EMT is the process by which cells lose their epithelial features and obtain a mesenchymal characteristic. Many growth factors participate in EMT, especially transforming growth factor- $\beta$ (TGF- $\beta$ ) $[2,3]$. During the progression of pulmonary fibrosis, most fibroblasts originate from lung epithelial cells, which undergo EMT and play a crucial role in fibrotic disease progression. The TGF- $\beta$ signaling pathway has been suggested to contribute to the EMT process and produce ECM proteins such as fibronectin (FN) [4]. Therefore, TGF- $\beta$ and EMT may be a hallmark of fibroblast activation.

A disintegrin and metalloproteinase 17 (ADAM17) is a transmembrane protein that plays a major role in the cleavage of extracellular domains of substrate proteins [5]. In physiological and pathophysiological processes, ADAM17 regulates some important membrane-bound proteins such as cytokines and growth factors [6]. A previous study demonstrated that ADAM17 regulates TGF- $\beta$-mediated EMT through cleavage of vasorin [7]. In addition, ADAM17-induced angiotensin-converting enzyme 2 (ACE-2) ectodomain shedding occurred in lung fibrogenesis, demonstrating that ADAM17 certainly participated in pulmonary fibrosis [8]. However, the role of ADAM17 in TGF- $\beta$-induced EMT in pulmonary fibrosis remain unidentified.

Connective tissue growth factor (CTGF) is an immediate early protein mediated by TGF- $\beta$, and it regulates the growth of fibroblasts and the secretion of ECM [9-11]. A previous study suggested that TGF- $\beta$ subcutaneous co-injection with CTGF induced sustained fibrosis in mice [12]. CTGF protein and mRNA are both enhanced in lung tissue obtained from IPF patients [13]. Moreover, integrin-linked kinase mediates the formation of CTGF-induced EMT in lung epithelial cells [14]. However, the relationship between ADAM17 and CTGF in TGF- $\beta$-induced EMT process in human lung epithelial cells remains unclear.

CCAAT enhancer-binding protein $\beta(C / \operatorname{EBP} \beta)$, a transcription factor that participates in the modulation of inflammatory protein expression in numerous cell types, is phosphorylated by RSK1, and protein kinase C (PKC) $[15,16]$. A previous study suggested that the CTGF promoter sequence includes AP-1 and C/EBP $\beta$ in zebrafish [17]. In addition, Weng et al. found that MEK inhibitor significantly attenuated CTGF expression in TGF- $\beta$-induced renal fibrosis in mice [18], but information on the responsibilities of RSK1 and C/EBP $\beta$ in TGF- $\beta$-induced CTGF expression in human lung epithelial cells remains limited. In the present study, data showed that TGF- $\beta$ might activate ERK, ADAM17, and RSK1 signaling pathways, which initiate C/EBP $\beta$ phosphorylation and the binding of $\mathrm{C} / \mathrm{EBP} \beta$ to the CTGF promoter region and lead to CTGF expression. Moreover, CTGF participates in TGF-induced FN expression in human lung epithelial cells.

\section{Results}

\subsection{TGF- $\beta$ Induced CTGF Expression in Human Lung Epithelial Cells}

TGF- $\beta$ contributes to initiating, maintaining, and amplifying the effects of other cytokines and chemoattractants related to the pathogenesis of lung injury [19]. CTGF is identified as an early phased gene, the expression of which is induced by TGF- $\beta$; moreover, its overproduction is suggested to play a crucial role in pathways leading to organ fibrosis $[10,20]$. In the present study, we investigated whether TGF- $\beta$ increases CTGF expression in human lung epithelial cells (A549). When A549 cells were treated with TGF- $\beta(10 \mathrm{ng} / \mathrm{mL})$ for $0-8 \mathrm{~h}$, CTGF expression significantly increased at $6 \mathrm{~h}$, with a maximal effect at $8 \mathrm{~h}$ (Figure 1A). Additionally, treating A549 cells with TGF- $\beta(0-10 \mathrm{ng} / \mathrm{mL})$ for $6 \mathrm{~h}$ in a dose-dependent manner induced CTGF expression (Figure 1B). The results indicated that TGF- $\beta$ enhanced CTGF protein expression in human lung epithelial cells. 
A

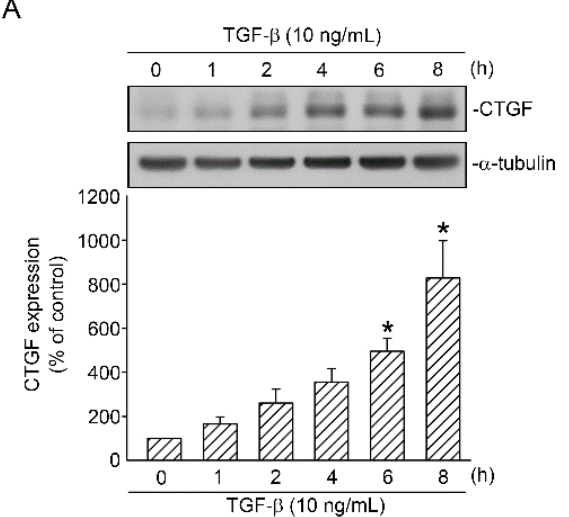

B

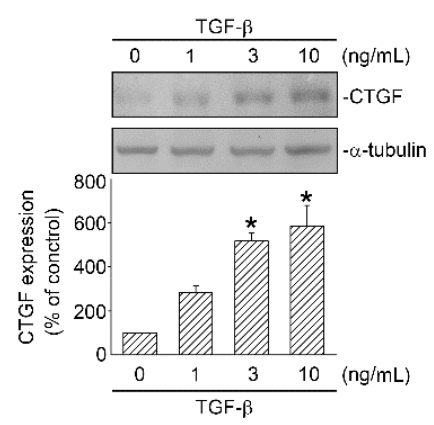

Figure 1. TGF- $\beta$-induced CTGF expression in human lung epithelial A549 cells. (A) A549 cells were treated with TGF- $\beta(10 \mathrm{ng} / \mathrm{mL})$ for $0-8 \mathrm{~h}$. Cell lysates were prepared, and CTGF and $\alpha$-tubulin antibodies were detected through Western blotting. Data are expressed as mean \pm SEM of three independent experiments. ${ }^{*} p<0.05$, compared with the control group without TGF- $\beta$ stimulation. (B) Cells were stimulated with TGF- $\beta(0-10 \mathrm{ng} / \mathrm{mL})$ for $6 \mathrm{~h}$. Cell lysates were prepared, and CTGF and $\alpha$-tubulin antibodies were detected through Western blotting. Data are presented as mean \pm SEM of three independent experiments. ${ }^{*} p<0.05$, compared with the control group without TGF- $\beta$ treatment.

\subsection{Involvement of ADAM17 Activation in TGF- $\beta$ Induced CTGF Expression in A549 Cells}

ADAM17 participates in several pathways, including the TGF- $\beta$ signaling pathway, and contributes to tissue fibrosis $[7,8]$. To determine whether ADAM17 mediates TGF- $\beta$-induced CTGF expression, an ADAM17 inhibitor (TAPI-0) was used. TAPI-0 can also inhibit matrix metalloprotease (MMP). Treatment of cells with TAPI-0 $(10 \mu \mathrm{M})$ inhibited TGF- $\beta$-induced CTGF expression by $70.4 \% \pm 18.3 \%$ (Figure 2A). In addition, when ADAM17 siRNA (25 nM) was used for a specific knockdown, ADAM17 siRNA attenuated TGF- $\beta$-induced CTGF expression by $60.1 \% \pm 10.4 \%$ (Figure $2 \mathrm{~B}$ ). Furthermore, ADAM17 siRNA markedly inhibited ADAM17 protein expression (Figure 2B). We further investigated whether TGF- $\beta$ induced ADAM17 activation. Phosphorylation of the ADAM17 Thr735 residue enhances cell surface presentation and the stability and activity of ADAM17 [21], and phosphorylated ADAM17 Thr735-specific antibody was used to investigate the phosphorylation of ADAM17. Stimulation of A549 cells with TGF- $\beta$ (10 ng/mL) in a time-dependent manner induced an increase in ADAM17 Thr735 phosphorylation, and the peak response was achieved at $10 \mathrm{~min}$ (Figure $2 \mathrm{C}$ ). These results indicated that ADAM17 was a downstream molecule of the TGF- $\beta$ signaling pathway and regulated TGF- $\beta$-induced CTGF expression in A549 cells. 
A

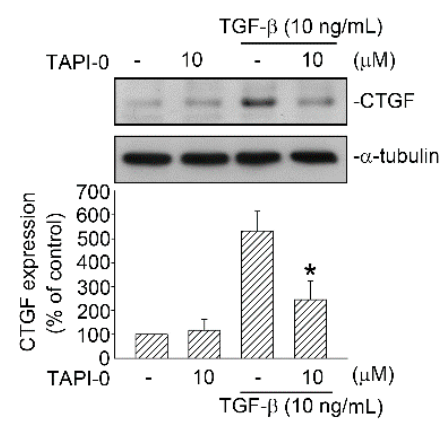

B

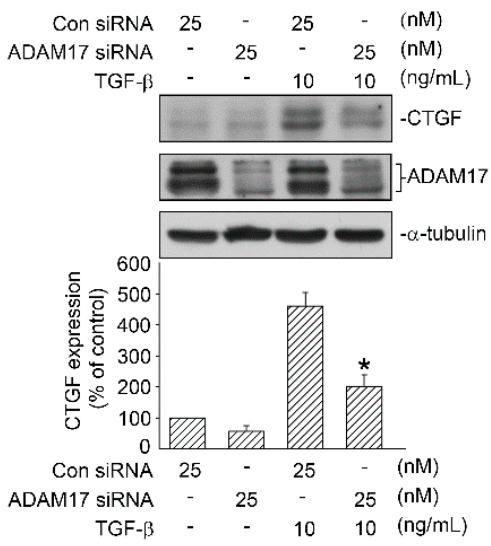

C

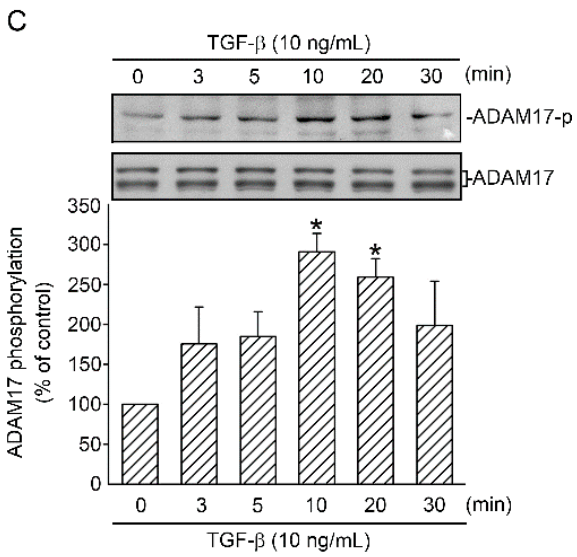

Figure 2. Participation of ADAM17 in TGF- $\beta$-induced CTGF expression in human lung epithelial A549 cells. (A) A549 cells were processed with the ADAM17 inhibitor TAPI-0 $(10 \mu \mathrm{M})$ for $20 \mathrm{~min}$. After $20 \mathrm{~min}$, the cells were stimulated with TGF- $\beta(10 \mathrm{ng} / \mathrm{mL})$ for an additional $6 \mathrm{~h}$. CTGF and $\alpha$-tubulin levels were detected in cell lysates through Western blotting. Data are expressed as mean \pm SEM of three independent experiments. ${ }^{*} p<0.05$, compared with the TGF- $\beta$ group without TAPI- 0 treatment. (B) A549 cells were transfected with $25 \mathrm{nM}$ control siRNA (con siRNA) and $25 \mathrm{nM}$ ADAM17 siRNA for $48 \mathrm{~h}$ before they were stimulated with TGF- $\beta(10 \mathrm{ng} / \mathrm{mL})$ for an additional $6 \mathrm{~h}$. CTGF and $\alpha$-tubulin levels were detected in cell lysates through Western blotting. Results are expressed as mean \pm SEM of three independent experiments. ${ }^{*} p<0.05$, compared with TGF- $\beta$ plus the control siRNA group. (C) Cells were stimulated with TGF- $\beta(10 \mathrm{ng} / \mathrm{mL})$ for 0-30 min, and then ADAM17 phosphorylation and ADAM17 were detected in cell lysates through Western blotting. Results are presented as mean \pm SEM of four independent experiments. ${ }^{*} p<0.05$, compared with the control group without TGF- $\beta$ treatment.

\subsection{Mediating Effects of ERK on TGF- $\beta$-Induced CTGF Expression and ADAM17 Phosphorylation}

ERK is a key mediator of several TGF- $\beta$-regulated cellular functions [22]. To confirm whether ERK phosphorylation mediates TGF- $\beta$-induced CTGF expression, A549 cells were processed with $10 \mu \mathrm{M}$ 
U0126 (an ERK inhibitor). Zhai et al. demonstrated that U0126 effectively inhibited the expression of p-ERK in A549 cells [23]. We further examine whether ERK participates in TGF- $\beta$-induced CTGF expression. After treatment with U0126 for $20 \mathrm{~min}$, the cells were treated with TGF- $\beta$ (10 ng/mL) for an additional $6 \mathrm{~h}$. U0126 $(10 \mu \mathrm{M})$ completely reduced TGF- $\beta$-induced CTGF expression (FIGURE 3A). Subsequently, an antibody specific for ERK phosphorylated at Tyr204 was used to define ERK phosphorylation. After A549 cells were processed with TGF- $\beta(10 \mathrm{ng} / \mathrm{mL})$ for 0-30 min, ERK Tyr204 phosphorylation increased at $5 \mathrm{~min}$, achieved a peak at $10 \mathrm{~min}$, and declined after $20 \mathrm{~min}$ of treatment (Figure 3B). A previous study suggested that ERK phosphorylates ADAM17 in kidney cells during profibrotic stimulation [24]. We evaluated the role of ERK in TGF- $\beta$-induced activation of ADAM17 in human lung epithelial cells. A549 cells were processed with U0126 $(10 \mu \mathrm{M})$ for $20 \mathrm{~min}$ and then treated with TGF- $\beta$ ( $10 \mathrm{ng} / \mathrm{mL}$ ) for $10 \mathrm{~min}$. As a result, ADAM17 phosphorylation was decreased (Figure $3 \mathrm{C}$ ). This result implied that TGF- $\beta$ activated ERK, which mediated TGF- $\beta$-induced CTGF expression and, in turn, might affect ADAM17 function.

A

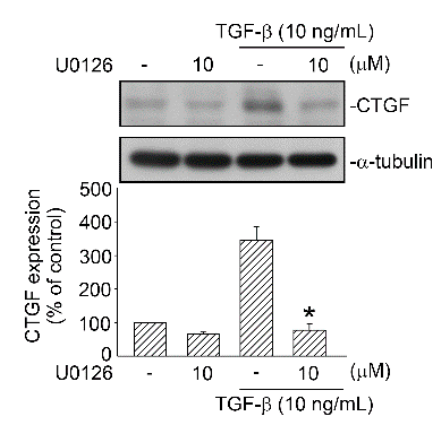

B

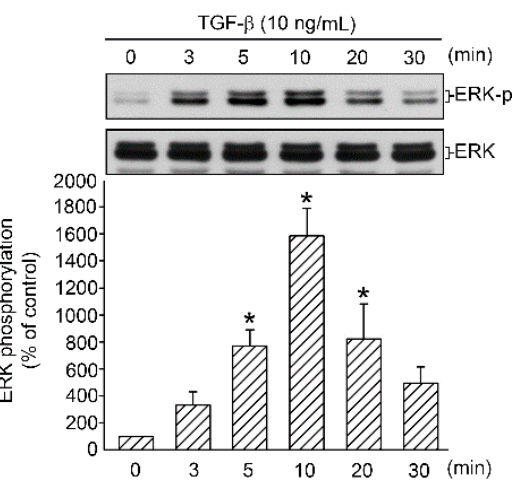

C

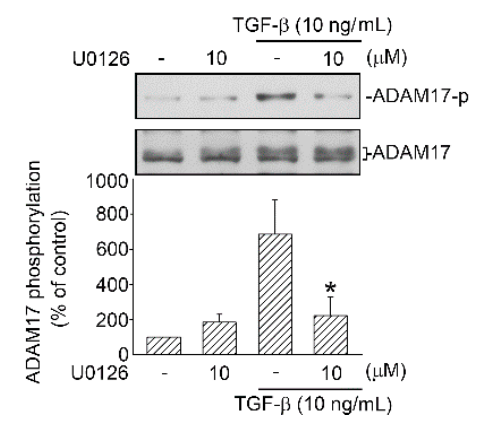

Figure 3. Participation of ERK in TGF- $\beta$-induced CTGF expression and ADAM17 activation in human lung epithelial A549 cells. (A) Cells were processed with the ERK inhibitor U0126 $(10 \mu \mathrm{M})$ for $20 \mathrm{~min}$ before they were stimulated with TGF- $\beta(10 \mathrm{ng} / \mathrm{mL})$ for an additional $6 \mathrm{~h}$. CTGF or $\alpha$-tubulin in cell 
lysates were immunodetected with specific antibodies. Data are expressed as mean \pm SEM of three independent experiments. ${ }^{*} p<0.05$, compared with the TGF- $\beta$ group without U0126 treatment. (B) A549 cells were stimulated with TGF- $\beta$ (10 ng/mL) for 0-30 min, and then the levels of ERK phosphorylation and ERK in cell lysates were immunodetected with specific antibodies. Data are presented as mean \pm SEM of four independent experiments. ${ }^{*} p<0.05$, compared with the control group without TGF- $\beta$ treatment. (C) Cells were treated with the ERK inhibitor U0126 (10 $\mu \mathrm{M})$ for $20 \mathrm{~min}$ before they were stimulated with TGF- $\beta(10 \mathrm{ng} / \mathrm{mL})$ for an additional $10 \mathrm{~min}$. Cell lysates were prepared, and specific antibodies for ADAM17 phosphorylation and ADAM17 were detected through Western blotting. Data are presented as mean \pm SEM of three independent experiments. ${ }^{*} p<0.05$, compared with the TGF- $\beta$ group without U0126 treatment.

\subsection{RSK1-Mediated TGF- $\beta$-Induced CTGF Expression}

Next, we confirmed whether RSK1 is involved in CTGF expression induced by TGF- $\beta$. TGF- $\beta$-induced CTGF expression was inhibited by $54.7 \% \pm 9.6 \%$ after A549 cells were transfected with RSK1 siRNA (25 nM) (Figure 4A). Additionally, when the cells were transfected with RSK1 siRNA (25 nM), the RSK1 expression decreased, indicating that RSK1 siRNA was functional (Figure 4A). Next, to investigate TGF- $\beta$-induced phosphorylation of RSK1, we used an antibody specific for RSK1 phosphorylated at Ser221. Incubation of A549 cells with TGF- $\beta$ (10 ng/mL) for 0-30 min time-dependently induced RSK1 phosphorylation, which increased at $5 \mathrm{~min}$, reached a maximum at 10 min, and declined after treatment for 20 min (Figure 4B). Subsequently, we examined whether ADAM17 mediates TGF- $\beta$-induced RSK1 phosphorylation. Pretreatment of cells with TAPI-0 (10 $\mu \mathrm{M})$ for 20 min attenuated TGF- $\beta$-induced RSK1 phosphorylation (Figure 4C). RSK1 is activated by the ERK signaling pathway [25], and, as mentioned above, ERK is involved in TGF- $\beta$-mediated CTGF expression in A549 cells. We then investigated whether RSK1 phosphorylation occurs through the ERK-mediated TGF- $\beta$ signaling pathway and found that TGF- $\beta$-induced RSK1 phosphorylation was inhibited by U0126 $(10 \mu \mathrm{M})$, and RSK1 phosphorylation decreased by $81.0 \% \pm 9.2 \%$ (Figure $4 \mathrm{D})$. These data revealed that in addition to ADAM17 and ERK, RSK1 is involved in TGF- $\beta$-induced CTGF expression.
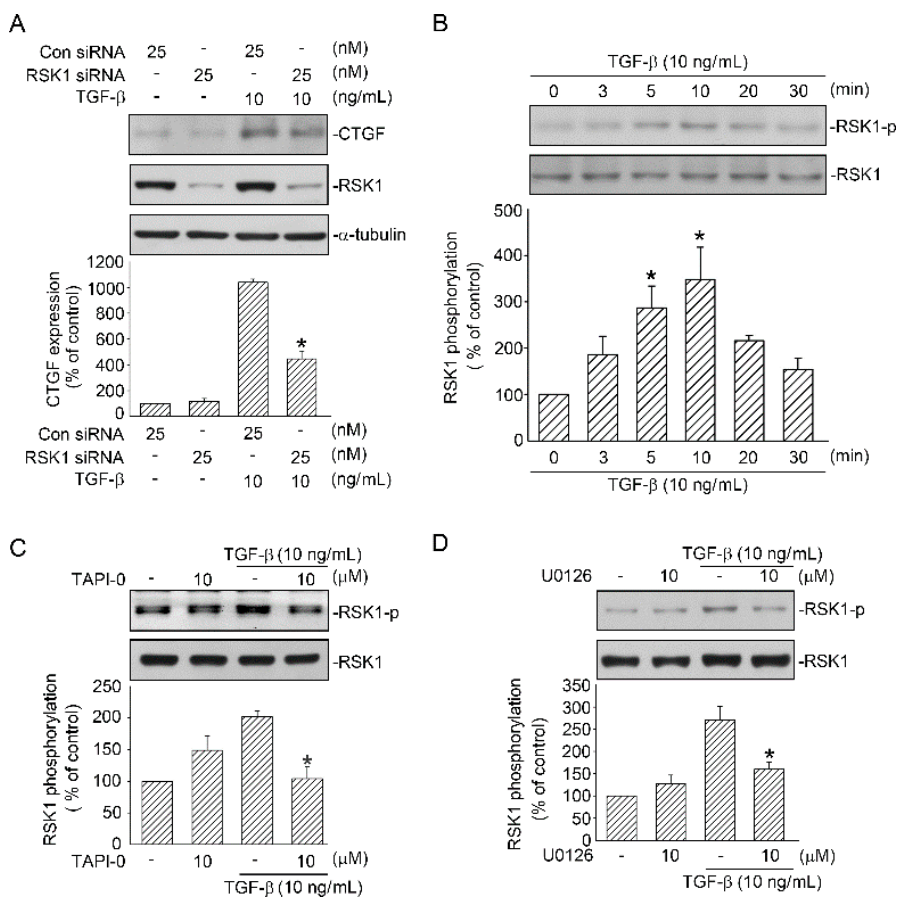

Figure 4. Involvement of RSK1 activation in TGF- $\beta$-induced CTGF expression through the ERK/ADAM17 pathway in human lung epithelial A549 cells. (A) Cells were transfected with $25 \mathrm{nM}$ 
control siRNA (con siRNA) and 25 nM RSK1 siRNA for $48 \mathrm{~h}$ before they were stimulated with TGF- $\beta$ $(10 \mathrm{ng} / \mathrm{mL})$ for an additional $6 \mathrm{~h}$. Cell lysates were prepared, and specific antibodies for CTGF and $\alpha$-tubulin were detected through Western blotting. Results are expressed as mean \pm SEM of three independent experiments. ${ }^{*} p<0.05$, compared with TGF- $\beta$ plus the control siRNA group. (B) Cells were stimulated with TGF- $\beta$ (10 ng/mL) for 0-30 min, and then the levels of RSK1 phosphorylation and RSK1 in cell lysates were immunodetected with specific antibodies. Results are presented as mean \pm SEM of three independent experiments. ${ }^{*} p<0.05$, compared with the control group without TGF- $\beta$ treatment. (C) Cells were treated with the ADAM17 inhibitor TAPI- $0(10 \mu \mathrm{M})$ for 20 min before they were stimulated with TGF- $\beta(10 \mathrm{ng} / \mathrm{mL})$ for an additional $10 \mathrm{~min}$. RSK1 phosphorylation and RSK1 in cell lysates were immunodetected with specific antibodies. Results are expressed as mean \pm SEM of four independent experiments. ${ }^{*} p<0.05$, compared with the TGF- $\beta$ group without TAPI- 0 treatment. (D) Cells were pretreated with U0126 $(10 \mu \mathrm{M})$ for $20 \mathrm{~min}$ before they were stimulated with TGF- $\beta$ (10 ng/mL) for an additional $10 \mathrm{~min}$. RSK1 phosphorylation and RSK1 in cell lysates were immunodetected with specific antibodies. Results are presented as mean \pm SEM of three independent experiments. ${ }^{*} p<0.05$, compared with the TGF- $\beta$ group without U0126 treatment.

\subsection{Role of C/EBP $\beta$ in TGF- $\beta$-Induced CTGF}

Chiou et al. (2006) proved the existence of some transcription factor binding sites, including $\mathrm{C} / \mathrm{EBP} \beta$, on the CTGF promoter [17]. To elucidate whether C/EBP $\beta$ participates in TGF- $\beta$-induced CTGF expression, $C / E B P \beta$ siRNA was used. When the cells were transfected with $C / E B P \beta$ siRNA (50 nM), TGF- $\beta$-induced CTGF expression was attenuated (Figure $5 \mathrm{~A}$ ). We then investigated C/EBP $\beta$ phosphorylation by using C/EBP $\beta$ Ser105 phosphorylated antibody. C/EBP $\beta$ phosphorylation increased and reached a peak at $20 \mathrm{~min}$ (Figure 5B). Next, we performed ChIP to ascertain the role of C/EBP $\beta$ in TGF- $\beta$-induced CTGF expression. We discovered that treatment of the cells with TGF- $\beta$ (10 ng/mL) for 20 min enhanced the binding of $\mathrm{C} / \mathrm{EBP} \beta$ on the CTGF promoter, which exhibits a 2.5-fold increase in $\mathrm{C} / \mathrm{EBP} \beta$-binding levels (Figure $5 \mathrm{C}$ ). Taken together, these data suggested that $\mathrm{C} / \mathrm{EBP} \beta$ binds to the CTGF promoter when activated by TGF- $\beta$, which in turn induced CTGF expression. 
A

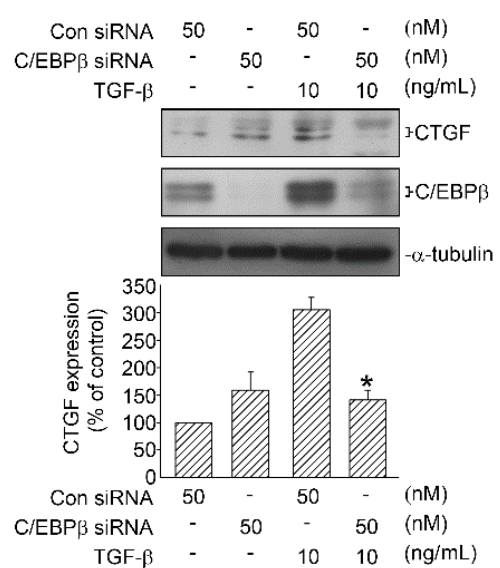

B

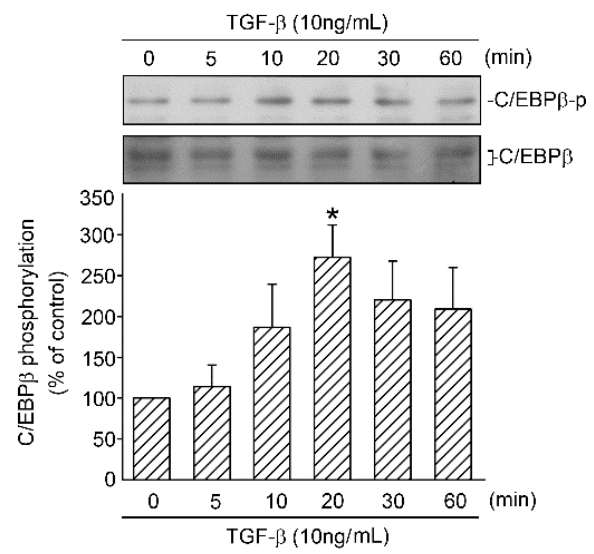

C

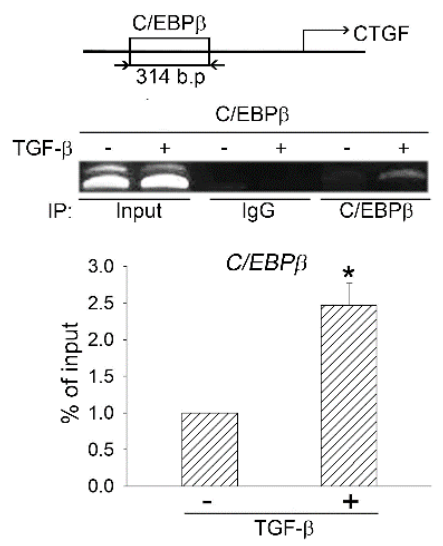

Figure 5. Participation of C/EBP $\beta$ in TGF- $\beta$-induced CTGF expression in human lung epithelial A549 cells. (A) A549 cells were transfected with $50 \mathrm{nM}$ control siRNA (con siRNA) and C/EBP $\beta$ siRNA $(50 \mathrm{nM})$ for $48 \mathrm{~h}$ before they were stimulated with TGF- $\beta(10 \mathrm{ng} / \mathrm{mL})$ for an additional $6 \mathrm{~h}$. CTGF and $\alpha$-tubulin levels were detected in cell lysates through Western blotting. Results are presented as mean \pm SEM of four independent experiments. ${ }^{*} p<0.05$, compared with TGF- $\beta$ plus the control siRNA group. (B) Cells were stimulated with TGF- $\beta(10 \mathrm{ng} / \mathrm{mL})$ for 0-60 min, after which the levels of C/EBP $\beta$ phosphorylation and $\mathrm{C} / \mathrm{EBP} \beta$ in cell lysates were immunodetected with specific antibodies. Results are presented as mean \pm SEM of five independent experiments. ${ }^{*} p<0.05$, compared with the control group without TGF- $\beta$ treatment. (C) Incubated cells were stimulated with TGF- $\beta$ (10 ng/mL) for $20 \mathrm{~min}$ and detected using the ChIP assay, as mentioned in the "Materials and Methods" section. The typical traces indicated the three independent experiments that yielded similar results. Results are presented as mean \pm SEM of three independent experiments. ${ }^{*} p<0.05$, compared with the control group without TGF- $\beta$ treatment. 


\subsection{Activation of C/EBP $\beta$ by TGF- $\beta$ through ERK, ADAM17, and RSK1}

A recent study suggested that C/EBP $\beta$ can be phosphorylated by RSK1 in human lung epithelial cells [15]. As mentioned above, TGF- $\beta$-induced RSK1 phosphorylation was mediated by ERK and ADAM17. Thus, we treated A549 cells with U0126 $(10 \mu \mathrm{M})$, TAPI-0 $(10 \mu \mathrm{M})$, or RSK1 siRNA (50 nM) and found that phosphorylated C/EBP $\beta$ at Ser105 was attenuated, respectively (Figure 6A-C). These results implied that TGF- $\beta$-induced C/EBP $\beta$ was a downstream molecule of the ERK/ADAM17/RSK1 pathway.

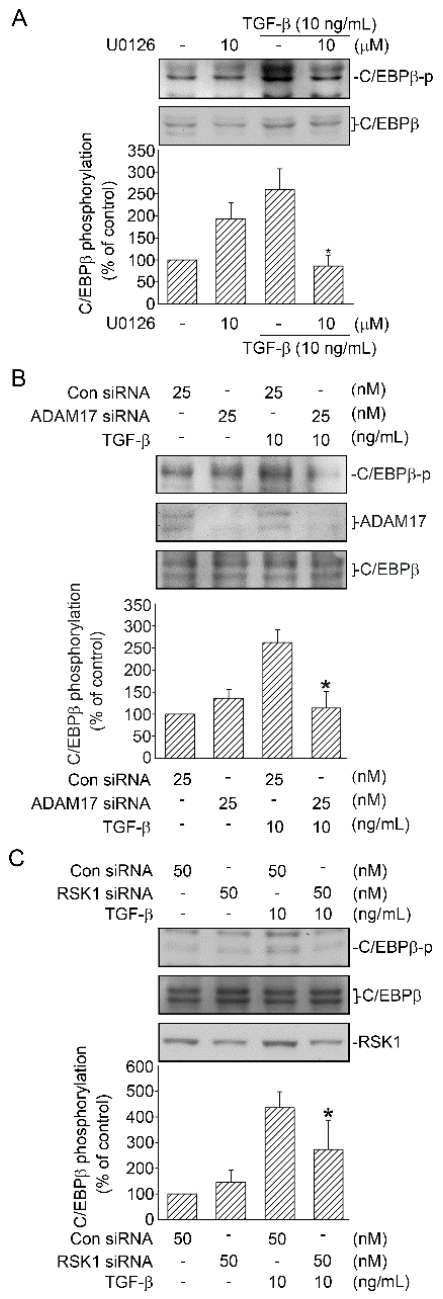

Figure 6. ERK, ADAM17, and RSK1 mediate TGF- $\beta$-induced C/EBP $\beta$ in human lung epithelial A549 cells. (A) A549 cells were processed with the ERK inhibitor U0126 (10 $\mu \mathrm{M})$ for $20 \mathrm{~min}$. After $20 \mathrm{~min}$, the cells were treated with TGF- $\beta(10 \mathrm{ng} / \mathrm{mL})$ for an additional $20 \mathrm{~min}$. C/EBP $\beta$ phosphorylation and C/EBP $\beta$ levels in cell lysates were immunodetected with specific antibodies. Data are expressed as mean \pm SEM of three independent experiments. ${ }^{*} p<0.05$, compared the TGF- $\beta$ group without U0126 treatment. (B) A549 cells were transfected with control siRNA (con siRNA) and ADAM17 siRNA ( $25 \mathrm{nM})$. After $24 \mathrm{~h}$, the cells were stimulated with TGF- $\beta(10 \mathrm{ng} / \mathrm{mL})$ for an additional $20 \mathrm{~min}$. Cell lysates were prepared, and specific antibodies for C/EBP $\beta$ phosphorylation and C/EBP $\beta$ were immunodetected. Data are expressed as mean \pm SEM of three independent experiments. ${ }^{*} p<0.05$, compared with TGF- $\beta$ plus the control siRNA group. (C) Cells were transfected with control siRNA (con siRNA) and RSK1 siRNA $(50 \mathrm{nM})$ for $24 \mathrm{~h}$ before they were processed with TGF- $\beta(10 \mathrm{ng} / \mathrm{mL})$ for an additional $20 \mathrm{~min}$. C/EBP $\beta$ phosphorylation and C/EBP $\beta$ were detected in cell lysates through Western blotting. Data are expressed as mean \pm SEM of three independent experiments. ${ }^{*} p<0.05$, compared with TGF- $\beta$ plus the control siRNA group. 


\subsection{TGF- $\beta$-Induced EMT Process in Human Lung Epithelial Cells}

During EMT, TGF- $\beta$ signaling pathway induces the expression of the growth-inhibited gene. The Smad-dependent transcriptional process then gradually attenuates the epithelial gene (such as E-cadherin) and activates the mesenchymal gene (such as FN) [3]. Therefore, we investigated the change in mRNA of the epithelial and mesenchymal genes through qPCR. After stimulation with TGF- $\beta 10 \mathrm{ng} / \mathrm{mL}$ ) for $0-48 \mathrm{~h}$, the expression of E-cadherin and FN mRNA in A549 cells was examined. The results revealed that E-cadherin mRNA expression decreased (Figure 7A), whereas the expression of FN mRNA increased (Figure 7B). Moreover, we further found that TGF- $\beta$ induced CTGF mRNA expression after $4 \mathrm{~h}$ treatment (Figure 7C). According to these data, TGF- $\beta$ induced CTGF expression as well as EMT in A549 cells.

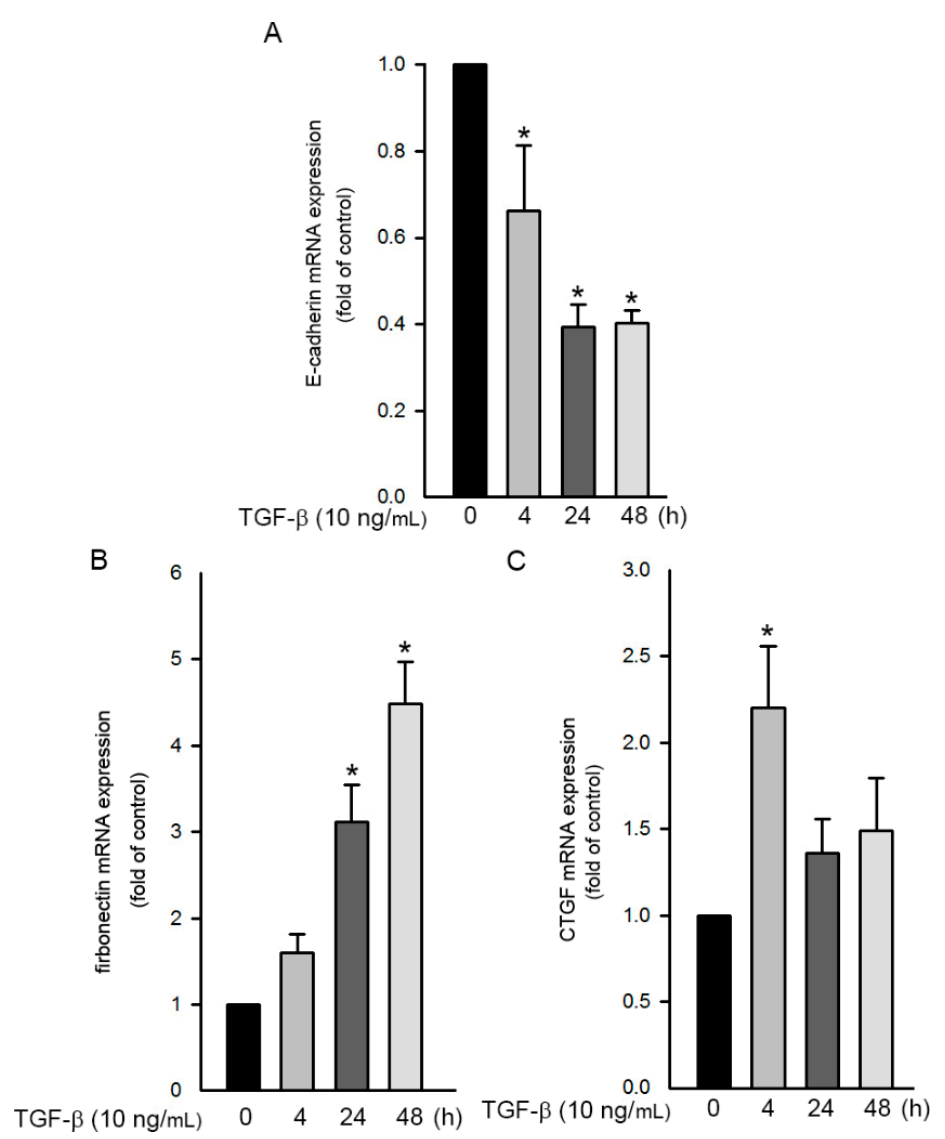

Figure 7. TGF- $\beta$-induced change in EMT-related mRNA levels in human lung epithelial A549 cells. (A) Cells were stimulated with TGF- $\beta(10 \mathrm{ng} / \mathrm{mL})$ for $0-48 \mathrm{~h}$. Total RNA was isolated and E-cadherin mRNA was determined using qRT-PCR. Results are presented as mean \pm SEM of three independent experiments. (B) Cells were stimulated with TGF- $\beta(10 \mathrm{ng} / \mathrm{mL})$ for $0-48 \mathrm{~h}$. Total RNA was isolated, and FN mRNA was determined through qRT-PCR. Data are presented as mean \pm SEM of three independent experiments. ${ }^{*} p<0.05$, compared with the control group without TGF- $\beta$ treatment. (C) Cells were stimulated with TGF- $\beta(10 \mathrm{ng} / \mathrm{mL})$ for $0-48 \mathrm{~h}$. Total RNA was isolated, and CTGF mRNA was determined through qRT-PCR. Results are presented as mean $\pm \mathrm{SEM}$ of seven independent experiments.

\subsection{Involvement of ADAM17 and CTGF in TGF- $\beta$-Induced FN Expression}

As mentioned above, FN is a mesenchymal marker that increased during TGF- $\beta$-induced EMT in human lung epithelial cells. In the present study, when A549 cells were stimulated with TGF- $\beta$ $10 \mathrm{ng} / \mathrm{mL}$ ) for $0-48 \mathrm{~h}$, FN protein was expressed time-dependently and peaked at $48 \mathrm{~h}$ (Figure $8 \mathrm{~A}$ ). Next, we investigated whether ADAM17 is involved in TGF- $\beta$-induced FN protein expression. We discovered 
that treatment of cells with ADAM17 siRNA $(25 \mathrm{nM})$ reduced TGF- $\beta$-induced FN protein expression (Figure $8 \mathrm{~B}$ ). In addition, we examined the role of CTGF in TGF- $\beta$-induced FN protein expression. Figure $8 \mathrm{C}$ shows that CTGF siRNA $(25 \mathrm{nM})$ inhibited FN expression. These data indicated that ADAM17 and CTGF regulated TGF- $\beta$-induced expression of FN in human lung epithelial cells.

A

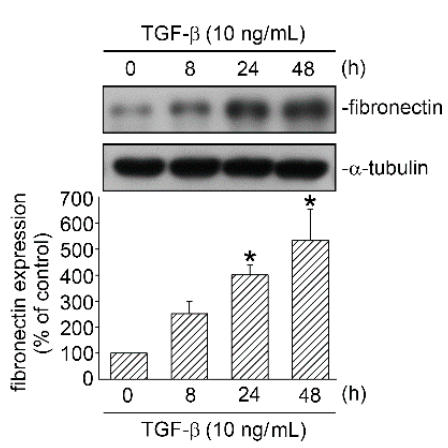

B

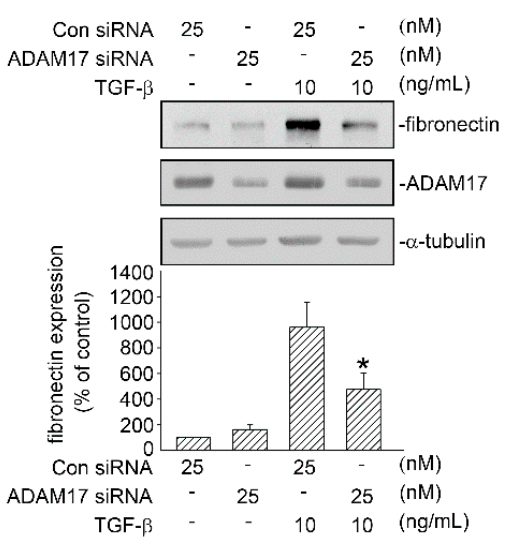

C

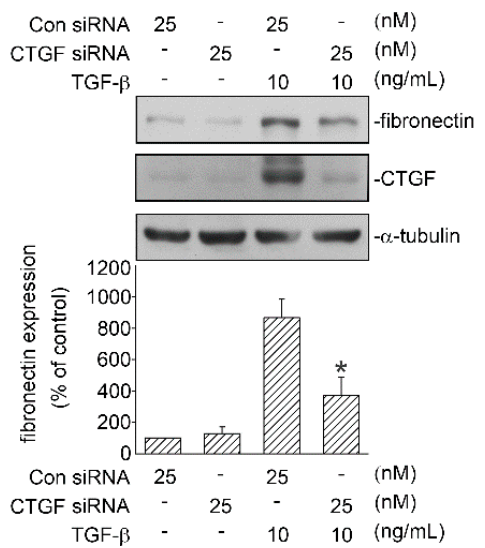

Figure 8. Involvement of ADAM17 and CTGF in TGF- $\beta$-induced FN expression in human lung epithelial A549 cells. (A) A549 cells were stimulated with TGF- $\beta$ (10 ng/mL) for $0-48 \mathrm{~h}$. FN and $\alpha$-tubulin levels were detected in cell lysates through Western blotting. Data are presented as mean \pm SEM of three independent experiments. ${ }^{*} p<0.05$, compared with the control group without TGF- $\beta$ treatment. (B) A549 cells were transfected with control siRNA (con siRNA) and ADAM17 siRNA $(25 \mathrm{nM})$. After $24 \mathrm{~h}$, the cells were stimulated with TGF- $\beta(10 \mathrm{ng} / \mathrm{mL})$ for an additional $48 \mathrm{~h}$. FN and $\alpha$-tubulin levels were detected through Western blotting. Results are presented as mean \pm SEM of three independent experiments. ${ }^{*} p<0.05$, compared with TGF- $\beta$ plus the control siRNA group. (C) Cells were transfected with control siRNA (con siRNA) and CTGF siRNA ( $25 \mathrm{nM}$ ). After $24 \mathrm{~h}$, the cells were stimulated with TGF- $\beta(10 \mathrm{ng} / \mathrm{mL})$ for an additional $48 \mathrm{~h}$. FN and $\alpha$-tubulin levels were detected through Western blotting. Results are presented as mean \pm SEM of three independent experiments. * $p<0.05$, compared with TGF- $\beta$ plus the control siRNA group. 


\section{Discussion}

ADAM17 is a crucial converting enzyme involved in numerous cellular functions such as EMT. Increased ADAM17 expression is identified in several inflammatory diseases, cancers, and organ fibrotic changes including pulmonary fibrosis $[6,7,24,26,27]$. During the progression of chronic pulmonary fibrosis, the volume and ventilation of the lungs are gradually decreased due to abnormal proliferation of fibroblasts through the EMT process, which causes collagen deposition and finally leads to architectural distortion [28-30]. Blom et al. (2002) suggested that CTGF appeared to play the role of a modulator and comediator of biological functions induced by TGF- $\beta$, including fibrogenesis [9]. In addition, several studies have shown that EMT-like changes are induced by the CTGF expression in lung epithelial cells. Furthermore, both EMT and differentiation of fibroblasts to myofibroblasts could be stimulated by TGF- $\beta[9,14]$. Therefore, CTGF and EMT play major roles in TGF- $\beta$-induced lung fibrosis. Recently, Chang et al. (2015) proved that in stem cells from the apical papilla, MEK/ERK and ALK5/smad2 signaling pathways were activated by TGF- $\beta$, which influenced the collagen content, cell growth, and ALP activity [22]. Kim et al. (2007) confirmed that RSK1 was a downstream mediator of ERK and phosphorylated the rat form of C/EBP $\beta$ at Ser105 in the N-terminal domain [16]. Moreover, a study demonstrated that the CTGF promoter might be activated by C/EBP $\beta$ after treatment with insulin-like growth factor-I in the zebrafish liver cell line [17]. In the present study, we found that ERK, ADAM17, RSK1, and C/EBP $\beta$ participated in acute TGF- $\beta$-induced CTGF expression in human lung epithelial cells. Additionally, ADAM17 and CTGF mediated TGF- $\beta$-induced FN expression. The results suggested that these acute TGF- $\beta$-mediated factors might play a crucial role in the expression of CTGF and EMT. Identifying the pathway involved in ADAM17-mediated TGF- $\beta$-induced expression of CTGF and EMT in human lung epithelial cells is crucial.

Numerous studies have confirmed that ADAMs, especially ADAM17, play a major role in modulating tumor growth and metastasis through regulating cell signaling pathways. In the progression of carcinomas, epithelial cells lose their characteristics, which are substituted by those of mesenchymal cells through the EMT process that is induced by ECM and TGF- $\beta$. In addition, Malapeira et al. (2011) proved that ADAM17 regulated the TGF- $\beta$ signaling pathway through the cleavage of vasorin and finally modulated EMT [7,27]. ADAM17 participates in pulmonary fibrosis by inducing ACE-2 ectodomain shedding [8]. However, the relationship between ADAM17 and TGF- $\beta$-induced CTGF expression remains unclear. In the present study, treating cells with ADAM17 siRNA attenuated the TGF- $\beta$-induced CTGF expression in A549 cells. In addition, treatment with ADAM17 siRNA caused a decrease in the FN expression in A549 cells stimulated with TGF- $\beta$. Studies have shown that increased CTGF expression is investigated in patients with bronchopulmonary dysplasia and pulmonary fibrosis. Furthermore, CTGF expression might induce EMT-like changes in the adjacent epithelial cells when CTGF is overexpressed in lung fibroblasts $[14,31,32]$. The results of the present study showed that transfection of cells with CTGF siRNA reduced TGF- $\beta$-induced FN expression. Taken together, the results implied that ADAM17 and CTGF played crucial roles in TGF- $\beta$-induced FN expression in human lung epithelial cells.

The ERK pathway plays a major role in the progression of pulmonary fibrosis through regulating osteopontin, which is recognized as a proinflammatory and profibrotic cytokine and is usually activated by growth factors through their receptor tyrosine kinases. Moreover, ERK1/2 is highly activated in the lung tissue of a patient with early stage IPF [33,34]. Yang et al. (2016) suggested that in mice with schistosomiasis hepatic fibrosis, CTGF was induced by corilagin through the miR-21/Smad7/ERK signaling pathway [35]. Because RSK1 is a member of MAPKAPK, which are modulated by ERK and p38 MAPKs [36], we questioned whether RSK1 plays a role in ERK-mediated TGF- $\beta$-induced CTGF expression. In the present study, we found that treatment with the ERK inhibitor U0126 attenuated TGF- $\beta$-induced CTGF expression in A549 cells, and so did treatment with RSK1 siRNA. Additionally, stimulation with TGF- $\beta$ enhanced the phosphorylation of ERK and RSK1. Moreover, TGF- $\beta$-induced RSK1 phosphorylation decreased in the cells treated with U0126. Thus, ERK activation was involved in RSK1 phosphorylation and TGF- $\beta$-induced CTGF expression. A previous study showed that the 
expressed pro-ADAM17 is phosphorylated by ERK in intact cells [37]. To further examine the role of ADAM17 in the ERK/RSK1 pathway, we used the ERK inhibitor U0126 and ADAM17 inhibitor TAPI- 0 to treat A549 cells and found that ADAM17 phosphorylation and RSK1 phosphorylation were inhibited, respectively, suggesting that ERK mediated TGF- $\beta$-induced ADAM17 phosphorylation, and ADAM17 regulated TGF- $\beta$-induced RSK1 phosphorylation. Overall, our results demonstrated that TGF- $\beta$ enhanced CTGF expression through the ERK/ADAM17/RSK1 signaling pathway.

Chiou et al. (2006) suggested that the CTGF proximal promoter sequence included TATAA box, putative $\mathrm{AP}-1, \mathrm{C} / \mathrm{EBP} \alpha$, and $\mathrm{C} / \mathrm{EBP} \beta$ binding sites [17]. In addition, the promoter of the human collagen I gene has a binding site for $\mathrm{C} / \mathrm{EBP} \beta$. Collagen I is recognized as a crucial mediator for TGF- $\beta$ - and CTGF-induced fibrogenic processes [38]. However, the role of C/EBP $\beta$ in TGF- $\beta$-induced CTGF expression remains unclear. In the present study, we found that C/EBP $\beta$ markedly bound to the CTGF promoter upon TGF- $\beta$ stimulation. Furthermore, when the cells were transfected with C/EBP $\beta$ siRNA, TGF- $\beta$-induced CTGF expression was inhibited, demonstrating that C/EBP $\beta$ exerted a positive modulation on TGF- $\beta$-induced CTGF expression. We also found that treatment with U0126, ADAM17 siRNA, and RSK1 siRNA inhibited C/EBP $\beta$ phosphorylation, suggesting that TGF- $\beta$ induced C/EBP $\beta$ activation through the ERK/ADAM17/RSK1 pathway. Furthermore, the results of our study indicated that ADAM17 played a master role in TGF- $\beta$-induced CTGF expression and EMT through the ERK/RSK1/C/EBP $\beta$ pathway. In conclusion, TGF- $\beta$ activated the ERK/ADAM17/RSK1/C/EBP $\beta$ signaling pathway, after which it promoted the connection of $C / E B P \beta$ to the $C / E B P \beta$ site on the CTGF promoter region to regulate CTGF expression in human lung epithelial cells. Moreover, ADAM17 and CTGF participated in TGF- $\beta$-induced FN expression. Our results reveal a signaling pathway related to ADAM17, CTGF, and FN and can be used to interpret how TGF- $\beta$ induces the expression of CTGF and EMT, which may provide a new orientation for the treatment of IPF (Figure 9).

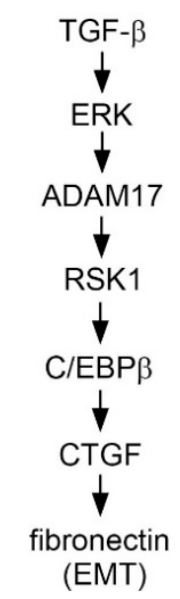

Figure 9. Simplified image displaying the results of TGF- $\beta$-induced CTGF expression mediated via the ERK/ADAM17/RSK1/C/EBP $\beta$ pathway in human lung epithelial cells. TGF- $\beta$ activated the ERK/ADAM17/RSK1/C/EBP $\beta$ signaling pathway, which in turn initiates binding of C/EBP $\beta$ to the CTGF promoter and ultimately induces CTGF expression in human lung epithelial cells. Moreover, ADAM17 and CTGF participated in TGF- $\beta$-induced FN expression.

\section{Materials and Methods}

\subsection{Materials}

The human lung epithelial cell line (A549) (Cat\# CCL-185, RRID:CVCL_0023) was purchased from the American Type Culture Collection (Manassas, VA, USA). Dulbecco's Modified Eagle's medium/Ham's F-12, fetal calf serum, and penicillin/streptomycin were obtained from Invitrogen Life Technologies (Carlsbad, CA, USA). TGF- $\beta$ was purchased from PeproTech (London, UK). U0126 was acquired from Calbiochem-Novabiochem (San Diego, CA, USA). TNF- $\alpha$ processing inhibitor-0 (TAPI-0) 
was obtained from Enzo Life Science (Farmindale, NY, USA). Lipofectamine 3000 and Lipofectamine Plus reagent as well as a minimum essential medium were purchased from Invitrogen Life Technologies. C/EBP $\beta$ small interfering RNA (siRNA), RSK1 siRNA, ADAM17 siRNA, and scrambled siRNA (control) were acquired from Sigma-Aldrich (St. Louis, MO, USA). An $\alpha$-tubulin antibody (Cat\# T5168, RRID:AB_477579) was obtained from Sigma-Aldrich (St. Louis, MO, USA). Antibodies specific for RSK1 (Cat\# sc-231, RRID:AB_632367) ERK (Cat\# sc-94, RRID:AB_2140110), ERK phosphorylated at Tyr204 (Cat\# sc-7383, RRID:AB_627545), CTGF (Cat\# sc-14939, RRID:AB_638805), and C/EBP $\beta$ Cat\# sc-7962, RRID:AB_626772; and anti-mouse (Cat\# sc-2005, RRID:AB_631736), anti-goat (Cat\# sc-2020, RRID:AB_631728), and anti-rabbit (Cat\# sc-2004, RRID:AB_631746) IgG-conjugated horseradish peroxidase antibodies, were obtained from Santa Cruz Biotechnology (Santa Cruz, CA, USA). Antibodies specific for ADAM17 (Cat\# ab2051, RRID:AB_302796), ADAM17 phosphorylation at Thr735 (Cat\# ab195828, RRID:AB_2750979), RSK1 phosphorylation at Ser221 (Cat\# sc-231, RRID:AB_632367), and fibronectin (Cat\# ab2413, RRID:AB_2262874) were purchased from Abcam (Cambridge, MA, USA). An antibody specific for C/EBP $\beta$ phosphorylated at Ser105 antibody (Cat\# Ap20701b, RRID:AB_2750980) was acquired from Abgent (San Diego, CA, USA). A nucleospin RNA kit was obtained from Macherey-Nagel (Bethlehem, PA, USA). A chromatin immunoprecipitation (ChIP) assay kit was acquired from Upstate Biotech Millipore (Lake Placid, NY, USA). All materials required for Western blotting were obtained from Bio-Rad (Hercules, CA, USA).

\subsection{Cell Culture}

Human lung epithelial (A549) cells were cultured as described previously [15]. In brief, A549 cells were seeded in Dulbecco's Modified Eagle's medium/Ham's F-12 nutrient mixture, containing $10 \%$ fetal calf serum, $100 \mathrm{U} / \mathrm{mL}$ penicillin, $250 \mu \mathrm{g} / \mathrm{mL}$ fungizone, and $100 \mu \mathrm{g} / \mathrm{mL}$ streptomycin, in a humidified incubator at $37^{\circ} \mathrm{C}$. Cells were passaged onto $60-\mathrm{mm}$ dishes for Western blotting and qRT-PCR or onto 100-mm dishes for the ChIP assay after achieving confluence.

\section{3. siRNAs Transfection}

A549 cells (2 105 cell/well) were transfected with scrambled siRNA, ADAM17 siRNA, RSK1 siRNA, C/EBP $\beta$ siRNA, and CTGF siRNA with lipofectamine 3000 reagents for $24 \mathrm{~h}$ according to the manufacturer's instructions. The medium was suctioned and substituted with fresh growth medium after siRNA transfection and then treated with TGF- $\beta$ for the indicated time intervals.

\subsection{Western Blotting}

A549 cells were treated with TAPI-0 or U0126 for 20 min or transfected with control siRNA, ADAM17 siRNA, RSK1 siRNA, C/EBP $\beta$ siRNA, or CTGF siRNA. After $24 \mathrm{~h}$, cells were treated with TGF- $\beta$. Immunoreactivity was assessed through Western blotting as described previously [15].

\subsection{Chromatin Immunoprecipitation Assay}

A549 cells were stimulated with TGF- $\beta(10 \mathrm{ng} / \mathrm{mL})$. After $20 \mathrm{~min}$, they were fixed with formaldehyde for an additional $10 \mathrm{~min}$. The C/EBP $\beta$ binding to the promoter region of CTGF was investigated using the ChIP assay, performed as previously described [15]. The primer sequences for PCR amplification on the promoter site of CTGF were C/EBP $\beta$, sense: $5^{\prime}$-AAT CAG GAG TGG TGC GAA GA-3' and antisense: 5'-AGC GGG GAA GAG TTG TTG TG-3'.

\subsection{RNA Isolation and RT-PCR}

According to the instructions, RNA was isolated from A549 cells. By using Moloney Murine Leukemia Virus Reverse Transcriptase (Toronto, ON, Canada), total RNA $(1 \mu \mathrm{g})$ was isolated for RT. Subsequently, $10 \mu \mathrm{g}$ cDNA of FN, CTGF, and E-cadherin was amplified using SYBR Green with a Rotor Gene Q system to investigate changes in mRNA. Primer sequences for FN were forward, $5^{\prime}$-ACC 
CAA TTC CTT GCT GGT ATC A-3' , and reverse, 5' -GTA TAT TCG GTT CCC GGT TCC-3'. The CTGF primer sequences were forward, 5' -CTG GCG GCT TAC CGA CTG-3' , and reverse, 5' -GGC TCT GCT TCT CTA GCC TG-3'. Primer sequences of E-cadherin were forward, 5' -GAG AAA CAG GAT GGC TGA AGG-3', and reverse, 5' -TGA GGA TGG TGT AAG CGA TGG-3' . Primer sequences of $\beta$-actin for the internal control were forward, 5' -CCA ATC TGC TGG AAG GTG G-3', and reverse, 5' -GAC TAC CTC ATG AAG ATC CT-3'.

\subsection{Statistical Analysis}

Data are presented as the mean \pm standard error of the mean (SEM) of at least three independent experiments. One-way analysis of variance followed by Dunnett's test was conducted to define diversities between means. A $p$ value of $<0.05$ was considered statistically significant.

Author Contributions: Conceptualization, S.-C.O., K.-J.B., W.-H.C., J.-Y.C., C.-H.L., H.-C.W. and B.-C.C.; Methodology, S.-C.O. and B.-C.C.; Software, S.-C.O.; Validation, S.-C.O. and B.-C.C.; Formal Analysis, S.-C.O. and B.-C.C.; Investigation, S.-C.O., K.-J.B., W.-H.C., J.-Y.C., C.-H.L., H.-C.W. and B.-C.C.; Data Curation, S.-C.O., K.-J.B., W.-H.C., J.-Y.C., C.-H.L., H.-C.W. and B.-C.C..; Writing, S.-C.O. All authors have read and agreed to the published version of the manuscript.

Funding: This work was supported by the Ministry of Science and Technology of Taiwan (MOST 105-2815-C-038-015-B, MOST 107-2320-B-038-047, MOST109-2320-B-038-068), Taipei Medical University Wan Fang Hospital (104 TMU-WFH-02-1), and the Higher Education Sprout Project by the Ministry of Education (MOE) in Taiwan (DP2-107-21121-01-T-01).

Acknowledgments: The authors thank the members of the laboratory of Chien-Huang Lin for their technical assistance.

Conflicts of Interest: The authors declare no conflict of interest.

\begin{tabular}{ll}
\multicolumn{2}{l}{ Abbreviations } \\
ADAM17 & A disintegrin and metalloproteinase 17 \\
ANOVA & Analysis of variance \\
C/EBP $\beta$ & CCAAT/enhancer-binding protein $\beta$ \\
ChIP & Chromatin immunoprecipitation \\
CTGF & Connective tissue growth factor \\
ECM & Extracellular matrix \\
EMT & Epithelial-mesenchymal transition \\
ERK & Extracellular signal-regulated kinase \\
FN & Fibronectin \\
IPF & Idiopathic pulmonary fibrosis \\
RSK & Ribosomal S6 kinases 1 \\
siRNA & Small interfering RNA \\
TGF- $\beta$ & Transforming growth factor- $\beta$
\end{tabular}

\section{References}

1. Rajasekaran, S.; Rajaguru, P.; Gandhi, P.S.S. MicroRNAs as potential targets for progressive pulmonary fibrosis. Front Pharmacol. 2015, 6. [CrossRef] [PubMed]

2. Giarnieri, E.; Bellipanni, G.; Macaluso, M.; Mancini, R.; Holstein, A.C.; Milanese, C.; Giovagnoli, M.R.; Giordano, A.; Russo, G. Review: Cell Dynamics in Malignant Pleural Effusions. J. Cell. Physiol. 2015, 230, 272-277. [CrossRef] [PubMed]

3. Gu, S.; Liu, Y.; Zhu, B.; Ding, K.; Yao, T.P.; Chen, F.; Zhan, L.; Xu, P.; Ehrlich, M.; Liang, T.; et al. Loss of alpha-Tubulin Acetylation Is Associated with TGF-beta-induced Epithelial-Mesenchymal Transition. J. Biol. Chem. 2016, 291, 5396-5405. [CrossRef] [PubMed]

4. Yang, G.; Lu, W.; Yu, D.; Sun, C.; Guo, J.; Li, Z.; Guan, F. Quantitative Analysis of Differential Proteome Expression in Epithelial-to-Mesenchymal Transition of Bladder Epithelial Cells Using SILAC Method. Molecules 2016, 21, 84. [CrossRef] [PubMed] 
5. Nitoiu, D.; Etheridge, S.L.; Kelsell, D.P. Insights into Desmosome Biology from Inherited Human Skin Disease and Cardiocutaneous Syndromes. Cell Commun. Adhes. 2014, 21, 129-140. [CrossRef]

6. Sun, J.; Jiang, J.; Lu, K.; Chen, Q.; Tao, D.; Chen, Z. Therapeutic potential of ADAM17 modulation in gastric cancer through regulation of the EGFR and TNF-alpha signalling pathways. Mol. Cell. Biochem. 2017, 426, 17-26. [CrossRef]

7. Malapeira, J.; Esselens, C.; Bech-Serra, J.J.; Canals, F.; Arribas, J. ADAM17 (TACE) regulates TGFbeta signaling through the cleavage of vasorin. Oncogene 2011, 30, 1912-1922. [CrossRef]

8. Uhal, B.D.; Nguyen, H.; Dang, M.; Gopallawa, I.; Jiang, J.; Dang, V.; Ono, S.; Morimoto, K. Abrogation of ER stress-induced apoptosis of alveolar epithelial cells by angiotensin 1-7. Am. J. Physiol. Lung Cell Mol. Physiol. 2013, 305, L33-L41. [CrossRef]

9. Blom, I.E.; Goldschmeding, R.; Leask, A. Gene regulation of connective tissue growth factor: New targets for antifibrotic therapy? Matrix Biol. 2002, 21, 473-482. [CrossRef]

10. Moussad, E.E.; Brigstock, D.R. Connective tissue growth factor: What's in a name? Mol. Genet. Metab. 2000, 71, 276-292. [CrossRef]

11. Ihn, H. Autocrine TGF-beta signaling in the pathogenesis of systemic sclerosis. J. Dermatol. Sci. 2008, 49, 103-113. [CrossRef] [PubMed]

12. Mori, T.; Kawara, S.; Shinozaki, M.; Hayashi, N.; Kakinuma, T.; Igarashi, A.; Takigawa, M.; Nakanishi, T.; Takehara, K. Role and interaction of connective tissue growth factor with transforming growth factor-beta in persistent fibrosis: A mouse fibrosis model. J. Cell. Physiol. 1999, 181, 153-159. [CrossRef]

13. Sakai, N.; Tager, A.M. Fibrosis of two: Epithelial cell-fibroblast interactions in pulmonary fibrosis. Biochim. Biophys. Acta 2013, 1832, 911-921. [CrossRef] [PubMed]

14. Shafieian, M.; Chen, S.; Wu, S. Integrin-linked kinase mediates CTGF-induced epithelial to mesenchymal transition in alveolar type II epithelial cells. Pediatr. Res. 2015, 77, 520-527. [CrossRef] [PubMed]

15. Lin, C.H.; Nai, P.L.; Bien, M.Y.; Yu, C.C.; Chen, B.C. Thrombin-induced CCAAT/enhancer-binding protein beta activation and IL-8/CXCL8 expression via MEKK1, ERK, and p90 ribosomal S6 kinase 1 in lung epithelial cells. J. Immunol. 2014, 192, 338-348. [CrossRef] [PubMed]

16. Kim, S.G.; Lee, S.J. PI3K, RSK, and mTOR signal networks for the GST gene regulation. Toxicol Sci 2007, 96, 206-213. [CrossRef]

17. Chiou, M.J.; Chao, T.T.; Wu, J.L.; Kuo, C.M.; Chen, J.Y. The physiological role of CTGF/CCN2 in zebrafish notochond development and biological analysis of the proximal promoter region. Biochem. Biophys. Res. Commun. 2006, 349, 750-758. [CrossRef]

18. Weng, L.; Wang, W.; Su, X.; Huang, Y.; Su, L.; Liu, M.; Sun, Y.; Yang, B.; Zhou, H. The Effect of cAMP-PKA Activation on TGF-beta1-Induced Profibrotic Signaling. Cell. Physiol. Biochem. 2015, 36, 1911-1927. [CrossRef]

19. Iyer, S.N.; Gurujeyalakshmi, G.; Giri, S.N. Effects of pirfenidone on transforming growth factor-beta gene expression at the transcriptional level in bleomycin hamster model of lung fibrosis. J. Pharmacol. Exp. Ther. 1999, 291, 367-373.

20. Phanish, M.K.; Winn, S.K.; Dockrell, M.E.C. Connective Tissue Growth Factor-(CTGF, CCN2)—A Marker, Mediator and Therapeutic Target for Renal Fibrosis. Nephron.. Exp. Nephrol. 2010, 114, E83-E92. [CrossRef]

21. Xu, P.; Liu, J.; Sakaki-Yumoto, M.; Derynck, R. TACE activation by MAPK-mediated regulation of cell surface dimerization and TIMP3 association. Sci. Signal 2012, 5, ra34. [CrossRef] [PubMed]

22. Chang, H.H.; Chang, M.C.; Wu, I.H.; Huang, G.F.; Huang, W.L.; Wang, Y.L.; Lee, S.Y.; Yeh, C.Y.; Guo, M.K.; Chan, C.P.; et al. Role of ALK5/Smad2/3 and MEK1/ERK Signaling in Transforming Growth Factor Beta 1-modulated Growth, Collagen Turnover, and Differentiation of Stem Cells from Apical Papilla of Human Tooth. J. Endod. 2015, 41, 1272-1280. [CrossRef] [PubMed]

23. Zhai, H.; Pan, T.; Yang, H.; Wang, H.; Wang, Y.J.E. Cadmium induces A549 cell migration and invasion by activating ERK. Exp. Ther. Med. 2019, 18, 1793-1799. [PubMed]

24. Bell, H.L.; Gooz, M. ADAM-17 Is Activated by the Mitogenic Protein Kinase ERK in a Model of Kidney Fibrosis. Am. J. Med. Sci. 2010, 339, 105-107.

25. Romeo, Y.; Zhang, X.; Roux, P.P. Regulation and function of the RSK family of protein kinases. Biochem. J. 2012, 441, 553-569. [CrossRef]

26. Pruessmeyer, J.; Ludwig, A. The good, the bad and the ugly substrates for ADAM10 and ADAM17 in brain pathology, inflammation and cancer. Semin. Cell Dev. Biol. 2009, 20, 164-174. [CrossRef] 
27. Saftig, P.; Reiss, K. The "A Disintegrin And Metalloproteases" ADAM10 and ADAM17: Novel drug targets with therapeutic potential? Eur. J. Cell Biol. 2011, 90, 527-535. [CrossRef]

28. Kreuter, M.; Bonella, F.; Wijsenbeek, M.; Maher, T.M.; Spagnolo, P. Pharmacological Treatment of Idiopathic Pulmonary Fibrosis: Current Approaches, Unsolved Issues, and Future Perspectives. Biomed. Res. Int. 2015, 2015, 329481. [CrossRef]

29. Ohkouchi, S.; Ono, M.; Kobayashi, M.; Hirano, T.; Tojo, Y.; Hisata, S.; Ichinose, M.; Irokawa, T.; Ogawa, H.; Kurosawa, H. Myriad Functions of Stanniocalcin-1 (STC1) Cover Multiple Therapeutic Targets in the Complicated Pathogenesis of Idiopathic Pulmonary Fibrosis (IPF). Clin. Med. Insights Circ. Respir. Pulm. Med. 2015, 9, 91-96. [CrossRef]

30. Chen, Y.L.; Zhang, X.; Bai, J.; Gai, L.; Ye, X.L.; Zhang, L.; Xu, Q.; Zhang, Y.X.; Xu, L.; Li, H.P.; et al. Sorafenib ameliorates bleomycin-induced pulmonary fibrosis: Potential roles in the inhibition of epithelial-mesenchymal transition and fibroblast activation. Cell Death Dis. 2013, 4, e665. [CrossRef]

31. Sonnylal, S.; Shi-Wen, X.; Leoni, P.; Naff, K.; Van Pelt, C.S.; Nakamura, H.; Leask, A.; Abraham, D.; Bou-Gharios, G.; de Crombrugghe, B. Selective expression of connective tissue growth factor in fibroblasts in vivo promotes systemic tissue fibrosis. Arthritis Rheum. 2010, 62, 1523-1532. [CrossRef] [PubMed]

32. Sonnylal, S.; Xu, S.; Jones, H.; Tam, A.; Sreeram, V.R.; Ponticos, M.; Norman, J.; Agrawal, P.; Abraham, D.; de Crombrugghe, B. Connective tissue growth factor causes EMT-like cell fate changes in vivo and in vitro. J. Cell Sci. 2013, 126, 2164-2175. [CrossRef] [PubMed]

33. Kato, A.; Okura, T.; Hamada, C.; Miyoshi, S.; Katayama, H.; Higaki, J.; Ito, R. Cell stress induces upregulation of osteopontin via the ERK pathway in type II alveolar epithelial cells. PLoS ONE 2014, 9, e100106. [CrossRef] [PubMed]

34. Watanabe-Takano, H.; Takano, K.; Hatano, M.; Tokuhisa, T.; Endo, T. DA-Raf-Mediated Suppression of the Ras-ERK Pathway Is Essential for TGF-beta1-Induced Epithelial-Mesenchymal Transition in Alveolar Epithelial Type 2 Cells. PLoS ONE 2015, 10, e0127888. [CrossRef] [PubMed]

35. Yang, F.; Wang, Y.; Xue, J.; Ma, Q.; Zhang, J.; Chen, Y.F.; Shang, Z.Z.; Li, Q.Q.; Zhang, S.L.; Zhao, L. Effect of Corilagin on the miR-21/smad7/ERK signaling pathway in a schistosomiasis-induced hepatic fibrosis mouse model. Parasitol. Int. 2016, 65, 308-315. [CrossRef]

36. Gogl, G.; Alexa, A.; Kiss, B.; Katona, G.; Kovacs, M.; Bodor, A.; Remenyi, A.; Nyitray, L. Structural Basis of Ribosomal S6 Kinase 1 (RSK1) Inhibition by S100B Protein: Modulation of the Extracellular Signal-Regulated Kinase (ERK) Signaling Cascade in a Calcium-Dependent Way. J. Biol. Chem. 2016, 291, 11-27. [CrossRef]

37. Soond, S.M.; Everson, B.; Riches, D.W.; Murphy, G. ERK-mediated phosphorylation of Thr735 in TNFalpha-converting enzyme and its potential role in TACE protein trafficking. J. Cell Sci. 2005, 118, 2371-2380. [CrossRef]

38. Lin, C.H.; Yu, M.C.; Tung, W.H.; Chen, T.T.; Yu, C.C.; Weng, C.M.; Tsai, Y.J.; Bai, K.J.; Hong, C.Y.; Chien, M.H.; et al. Connective tissue growth factor induces collagen I expression in human lung fibroblasts through the Rac1/MLK3/JNK/AP-1 pathway. Biochim. Biophys. Acta 2013, 1833, 2823-2833. [CrossRef]

Publisher's Note: MDPI stays neutral with regard to jurisdictional claims in published maps and institutional affiliations.

(C) 2020 by the authors. Licensee MDPI, Basel, Switzerland. This article is an open access article distributed under the terms and conditions of the Creative Commons Attribution (CC BY) license (http://creativecommons.org/licenses/by/4.0/). 